\title{
PENYULUHAN TENTANG PENGELOLAAN SAMPAH MENJADI PRODUK YANG BERNILAI GUNA
}

\section{COUNSELING ABOUT WASTE MANAGEMENT INTO A VALUE PRODUCT}

\author{
Vella Anggreana, Syarifah Sarah Alwiah, Neneng Purnamawati, \\ Roza Mildawati, Harmiyati Harmiyati
}

\author{
Program Studi Teknik Sipil, Fakultas Teknik, Universitas Islam Riau, \\ Pekanbaru, Indonesia \\ Email: anggreanav@gmail.com \\ (Diterima 02-03-2021; Disetujui 20-03-2021)
}

\begin{abstract}
ABSTRAK
Sampah telah menjadi masalah yang belum dapat diatasi di Indonesia. Pengelolaan sampah belum secara maksimal dilakukan. Penanganan permasalahan sampah di Kota Pekanbaru harus dimulai dari sumbernya yaitu rumah tangga dengan melibatkan partisipasi aktif masyarakat. Tujuan kegiatan yaitu memberikan pemahaman dan kemampuan masyarakat dalam melakukan pengelolaan sampah, sehingga memiliki kesadaran sosial untuk merubah perilaku dalam mengolah sampah. Pengurangan sampah dengan metoda 3R (Reduce, Reuse, Recycle) berbasis masyarakat lebih menekankan kepada cara pengurangan sampah yang dibuang oleh individu, rumah, atau kawasan seperti RT ataupun RW. Pengelolaan sampah yang efektif di rumah dapat membuat kita terbiasa mengatur alur masuk-keluar sampah. Tidak ada lagi sampah yang tergeletak begitu saja. Setiap sampah akan ditempatkan sesuai peruntukannya. Sampah organik diproses menjadi kompos, sedangkan sampah plastik/kaleng/botol dibersihkan dan dikirimkan untuk didaur ulang. Kegiatan pengelolaan sampah efektif ini akan membuat lingkungan menjadi bersih dan nyaman.
\end{abstract}

Kata kunci : Pengelolaan Sampah, Metode 3R

\section{ABSTRACT}

Garbage has become an insurmountable problem in Indonesia. Waste management has not been maximally carried out. Handling waste problems in Pekanbaru City must start from the source, namely the household by involving the active participation of the community. The purpose of the activity is to provide understanding and the ability of the community in carrying out waste management, so that they have social awareness to change their behavior in processing waste. Waste reduction with the community-based $3 R$ (Reduce, Reuse, Recycle) method emphasizes how to reduce waste disposes of by individuals, homes, or areas such as RT or RW. Effetive waste management at home can make us accustomed to managing the flow of waste in and out. No more trash lying around. Each piece of trash will be placed according to its designation. Organic waste is processed into compost, while plastic waste/cans/bottles are cleaned and sent for recycling. This effective waste management activity will make the environment clean and comfortable.

Keywords : Waste Management, 3R Method

\section{PENDAHULUAN}

Menurut Undang-undang No. 18 Tahun 2018, sampah adalah sisa kegiatan seharihari manusia dan/atau proses alam yang berbentuk padat. Pengelolaan sampah adalah semua kegiatan yang dilakukan untuk menangani sampah sejak ditimbulkan sampai dengan pembuangan akhir. Pengelolaan sampah menurut Undang-Undang Nomor 18 Tahun 2008 adalah suatu kegiatan yang sistematis, menyeluruh, dan berkesinambungan yang meliputi pengurangan dan penanganan. Pengurangan sampah meliputi kegiatan pembatasan timbunan, pendaur ulangan sampah, dan pemanfaatan kembali sampah. Adapun penanganan sampah meliputi kegiatan pemilahan, pengumpulan, pengangkutan, 
pengolahan, dan pemrosesan akhir sampah. Adapun tujuan dari pengelolaan sampah adalah meningkatkan kesehatan masyarakat dan kualitas lingkungan serta menjadikan sampah sebagai sumber daya.

Berdasarkan asalnya, sampah padat dapat digolongkan sebagai:

1. Sampah Organik.

Sampah organik terdiri atas bahan-bahan penyusun tumbuhan dan hewan yang diambil dari alam atau dihasilkan dari kegiatan pertanian, perikanan atau yang lain. Sampah ini dengan mudah diuraikan dalam proses alami. Sampah rumah tangga sebagian besar merupakan bahan organik. Termasuk sampah organik, misalnya sampah dari dapur, sisa tepung, sayuran, kulit buah, dan daun.

2. Sampah Anorganik.

Sampah anorganik berasal dari sumber daya alam tak terbaharui seperti mineral dan minyak bumi, atau dari proses industri. Beberapa dari bahan ini tidak terdapat di alam seperti plastik dan aluminium. Sebagian zat anorganik secara keseluruhan tidak dapat diuraikan oleh alam, sedang sebagian lainnya hanya dapat diuraikan dalam waktu yang sangat lama. Sampah jenis ini pada tingkat rumah tangga, misalnya berupa botol, botol plastik, tas plastik, dan kaleng.

Tahapan pengelolaan sampah yang dapat dilakukan:

a. Pencegahan dan Pengurangan Sampah dari Sumbernya. Kegiatan ini dimulai dengan kegiatan pemilahan atau pemisahan sampah organik dan anorganik dengan menyediakan tempat sampah organik dan anorganik di setiap rumah.

b. Pemanfaatan Kembali Kegiatan pemanfaatan sampah kembali, terdiri atas:

1) Pemanfaatan sampah organik, seperti composting (pengomposan). Sampah yang mudah membusuk dapat diubah menjadi pupuk kompos yang ramah lingkungan untuk melestarikan fungsi kawasan wisata.

2) Pemanfaatan sampah anorganik, baik secara langsung maupun tidak langsung. Pemanfaatan kembali secara langsung, misalnya pembuatan kerajinan yang berbahan baku dari barang bekas, atau kertas daur ulang. Sedangkan pemanfaatan kembali secara tidak langsung, misalnya menjual barang bekas seperti kertas, plastik, kaleng, koran bekas, botol, gelas, dan botol air minum dalam kemasan.

c. Tempat Pembuangan Sampah Akhir. Dengan pengelolaan sampah yang baik, sisa sampah akhir yang benar-benar tidak dapat dimanfaatkan lagi hanya sebesar $\pm 10 \%$. Kegiatan ini tentu saja akan menurunkan biaya pengangkutan sampah bagi pengelola 
kawasan, mengurangi luasan kebutuhan tempat untuk lokasi TPS, serta memperkecil permasalahan sampah yang saat ini dihadapi oleh banyak pemerintah daerah.

Menurut UU No 18 Tahun 2008 tentang pengelolaan sampah, dalam pengurangan sampah yang terdiri atas pembatasan terjadinya sampah (R1), guna ulang (R2), dan daur ulang (R3).

a. Pembatasan terjadinya sampah (Reduce) timbulan sampah. Upaya mengurangi terbentuknya limbah, termasuk penghematan dan pemilihan bahan yang dapat mengurangi kuantitas limbah serta sifat bahaya dari limbah.

b. Guna ulang (Reuse). Upaya yang dilakukan bila limbah tersebut dimanfaatkan kembali tanpa mengalami proses atau tanpa transformasi baru, misalnya botol minuman kembali menjadi botol minuman.

c. Daur ulang sampah (Recycle). Residu atau limbah yang tersisa atau tidak dapat dimanfaatkan secara langsung, kemudian diproses atau diolah untuk dapat dimanfaatkan, baik sebagai bahan baku maupun sebagai sumber energi. Misalnya botol minuman dilebur namun tetap dijadikan produk yang berbasis pada gelas. Bisa saja terjadi bahwa kualitas produk yang baru sudah mengalami penurunan dibanding produk asalnya.

Kompos merupakan hasil dekomposisi bahan-bahan organik oleh mikroorganisme pengurai seperti, bakteri, kapang atau cendawan, actinomycetes, dan lainnya dalam kondisi lingkungan tertentu. Kompos memiliki beberapa manfaat; salah satunya dapat memperbaiki struktur tanah, meningkatkan produktivitas tanaman, karena sumber hara yang dibutuhkan oleh tanaman menjadi tersedia. Selain itu, kompos juga meningkatkan kemampuan tanah dalam menyerap dan menyimpan air.

Dilihat dari manfaatnya, kompos dapat digunakan pupuk tanaman. Penggunaan kompos dalam usahatani dapat meningkatkan pendapatan usahatani dan kesejahteraan petani, karena kompos mudah didapatkan, bisa dibuat sendiri, dan juga dapat berperan dalam menangani masalah lingkungan. Pembuatan kompos sangatlah mudah, tidak memerlukan peralatan yang banyak, tidak memerlukan tempat yang luas, dan tidak memerlukan biaya yang banyak.

Sampah telah menjadi masalah yang belum dapat diatasi hingga saat ini di Indonesia. Pengelolaan sampah belum secara maksimal dilakukan. Penanganan permasalahan sampah di Kota Pekanbaru harus dimulai dari sumbernya yaitu rumah tangga dengan melibatkan partisipasi aktif masyarakat. Tujuan kegiatan yaitu memberikan pemahaman dan kemampuan masyarakat dalam melakukan pengelolaan sampah, sehingga memiliki 
Penyuluhan Tentang Pengelolaan Sampah Menjadi Produk yang Bernilai Guna

Vella Anggreana

kesadaran sosial untuk merubah perilaku dalam mengolah sampah.

Pengurangan sampah dengan metoda 3R berbasis masyarakat lebih menekankan kepada cara pengurangan sampah yang dibuang oleh individu, rumah, atau kawasan seperti RT ataupun RW. Dari pendekatan tersebut, maka didalam pelaksanaan pengelolaan sampah 3R berbasis masyarakat ada dua kegiatan yang harus dilakukan secara sinergi dan berkesinambungan, yaitu:

(1) proses pengelolaan aliran sampah dari mulai akan dikeluarkan oleh masyarakat.

(2) proses pemahaman masyarakat dalam pengelolaan sampah dengan metoda 3R.

Pengurangan sampah dengan program 3R dan replikasi best practise memang bukan hal mudah untuk dilakukan karena akan sangat bergantung pada kemauan masyarakat dalam merubah perilaku, yaitu dari pola pembuangan sampah konvensional menjadi pola pemilah sampah. Untuk itu, diperlukan berbagai upaya baik langsung maupun tidak langsung, seperti antara lain:

- Percontohan program 3R.

- Penyuluhan.

- Pemberdayaan dan pendampingan masyarakat.

- Pendidikan.

Dalam rangka memudahkan berbagai pihak untuk melaksanakan program pengurangan sampah tersebut, disusunlah suatu Pedoman Pengelolaan Sampah Terpadu Berbasis Masyarakat (3R) untuk skala rumah tangga dan skala kawasan.

Pengelolaan sampah yang efektif di rumah dapat membuat kita terbiasa mengatur alur masuk-keluar sampah. Tidak ada lagi sampah yang tergeletak begitu saja. Setiap sampah akan ditempatkan sesuai peruntukannya. Sampah organik diproses menjadi kompos, sedangkan sampah plastik/kaleng/botol dibersihkan dan dikirimkan untuk didaur ulang. Kegiatan pengelolaan sampah efektif ini akan membuat lingkungan menjadi bersih dan nyaman.

Tujuan kegiatan ini yaitu untuk memberikan informasi kepada masyarakat terkait program yang dilaksanakan, yaitu mengenai cara pengolahan sampah menjadi produk yang berdaya guna hingga dapat memberikan manfaat kepada masyarakat dan mengurangi pencemaran lingkungan di masyarakat.

Manfaat diadakannya kegiatan ini yaitu diharapkan dapat menambah pendapatan masyarakat, sebagai upaya pencegahan penyakit, lingkungan menjadi bersih dan nyaman 
Dampak negatif yang dapat ditimbulkan oleh volume sampah yang tinggi yang tidak dikelola dengan baik adalah gangguan kesehatan, menurunkan kualitas lingkungan, menurunkan estetika lingkungan dan terhambatnya pembangunan negara. Agar pengelolaan sampah berlangsung dengan baik dan mencapai tujuan yang diinginkan, maka setiap kegiatan pengelolaan sampah harus mengikuti filosofi pengelolaan sampah. Filosofi pengelolaan sampah sudah kita kenal adalah bahwa semakin sedikit dan semakin dekat sampah dikelola dari sumbernya, maka pengelolaannya akan menjadi lebih mudah dan baik, serta lingkungan yang terkena dampak juga semakin sedikit.

Dampak negatif dari sampah anorganik:

1. Pengelolaan sampah yang kurang baik akan membentuk lingkungan yang kurang menyenangkan bagi masyarakat: bau yang tidak sedap dan pemandangan yang buruk karena sampah bertebaran dimana-mana. Memberikan dampak negatif terhadap estetika lingkungan.

2. Pengelolaan sampah yang tidak memadai menyebabkan rendahnya tingkat kesehatan masyarakat. Hal penting di sini adalah meningkatnya pembiayaan secara langsung (untuk mengobati orang sakit), dan pembiayaan secara tidak langsung (tidak masuk kerja, rendahnya produktivitas).

3. Pembuangan sampah padat ke badan air dapat menyebabkan banjir dan akan memberikan dampak bagi fasilitas pelayanan umum seperti jalan, jembatan, drainase, dan lain-lain.

4. Infrastruktur lain dapat juga dipengaruhi oleh pengelolaan sampah yang tidak memadai, seperti tingginya biaya yang diperlukan untuk pengolahan air. Jika sarana penampungan sampah kurang atau tidak efisien, orang akan cenderung membuang sampahnya di jalan. Hal ini mengakibatkan jalan perlu lebih sering dibersihkan dan diperbaiki.

\section{BAHAN DAN METODE}

Kegiatan Pengabdian Kepada Masyarakat (PKM) dilakukan di salah satu rumah warga RT 03 RW 04 Kelurahan Sidomulyo Barat Kecamatan Tuahmadani Kota Pekanbaru. Kegiatan ini dilaksanakan pada hari Selasa, tanggal 19 Januari 2021.

Metode yang digunakan dalam kegiatan PKM yaitu dengan cara mempresentasikan materi penyuluhan tentang Pengelolaan Sampah Menjadi Produk yang Bernilai Guna. Selain itu, juga langsung disosialisasikan bagaimana cara mengolah sampah tersebut menjadi pupuk kompos agar dapat langsung memberikan manfaat bagi peserta penyuluhan 
Penyuluhan Tentang Pengelolaan Sampah Menjadi Produk yang Bernilai Guna

Vella Anggreana

di RT 03 RW 04 Kelurahan Sidomulyo Barat Kecamatan Tuahmadani Kota Pekanbaru.

\section{HASIL DAN PEMBAHASAN}

Sebelum dimulainya presentasi mengenai penyuluhan Pengelolaan Sampah Menjadi Produk yang Bernilai Guna, masyarakat yang mengikuti kegiatan ini diberikan salinan mengenai latar belakang penyuluhan beserta cara mengolah sampah rumah tangga agar sampah tersebut memiliki nilai yang berdaya guna. Setelah itu, masyarakat juga mendengarkan dengan seksama penjelasan berikut langkah-langkah pengolahan sampah yang selama ini dibuang sehingga tidak dapat dimanfaatkan dengan baik.

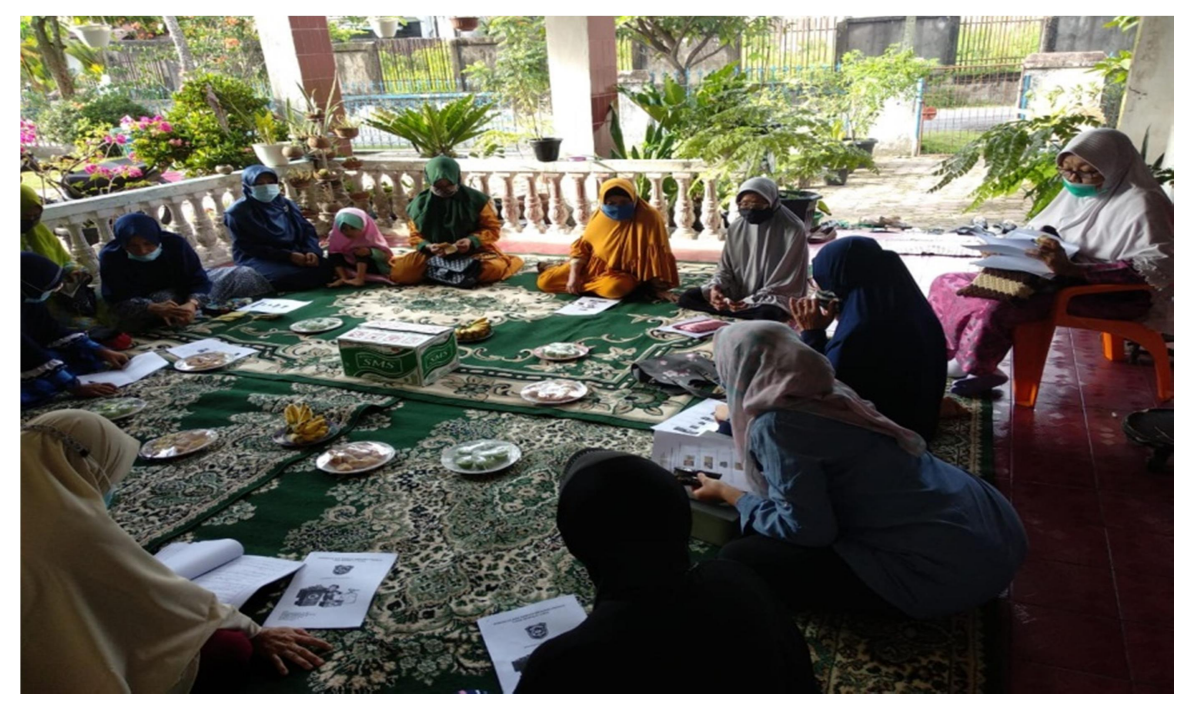

Gambar 1. Antusias warga mengikuti penyuluhan

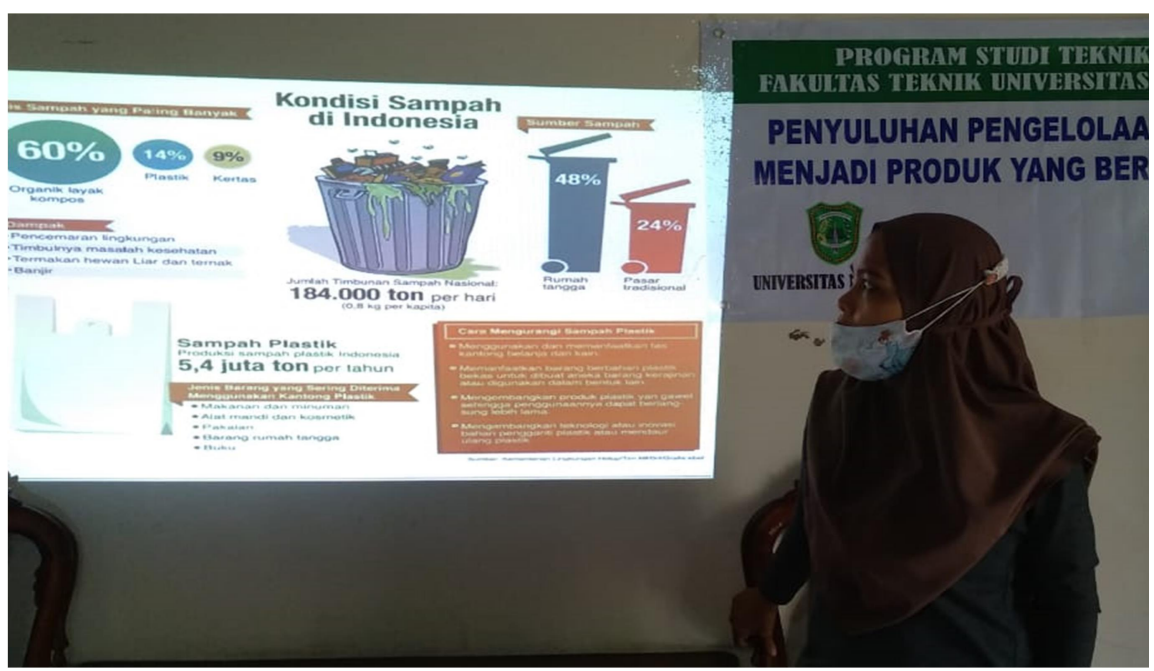

Gambar 2. Penjelasan Materi Sosialisasi 
Dari penjelasan yang dipaparkan, menurut data yang didapatkan dari Dinas Lingkungan Hidup dan Kehutanan Provinsi Riau, persentase sampah masuk Tempat Pembuangan Akhir (TPA) dapat dilihat pada Tabel 1.

Tabel 1. Persentase sampah masuk TPA

\begin{tabular}{lc}
\hline \multicolumn{1}{c}{ Nama Kabupaten/Kota } & Persentase Sampah Masuk TPA \\
\hline Pekanbaru & 44,43 \\
Dumai & 16,81 \\
Pelalawan & 8,8 \\
Kuantan Singingi & 7,16 \\
Kepulauan Meranti & 5,5 \\
Bengkalis & 4,27 \\
Indragiri Hulu & 4,18 \\
Kampar & 4,14 \\
Siak & 4,06 \\
Indragiri Hilir & 3,56 \\
Rokan Hilir & 3,45 \\
Rokan Hulu & 2,96 \\
\hline
\end{tabular}

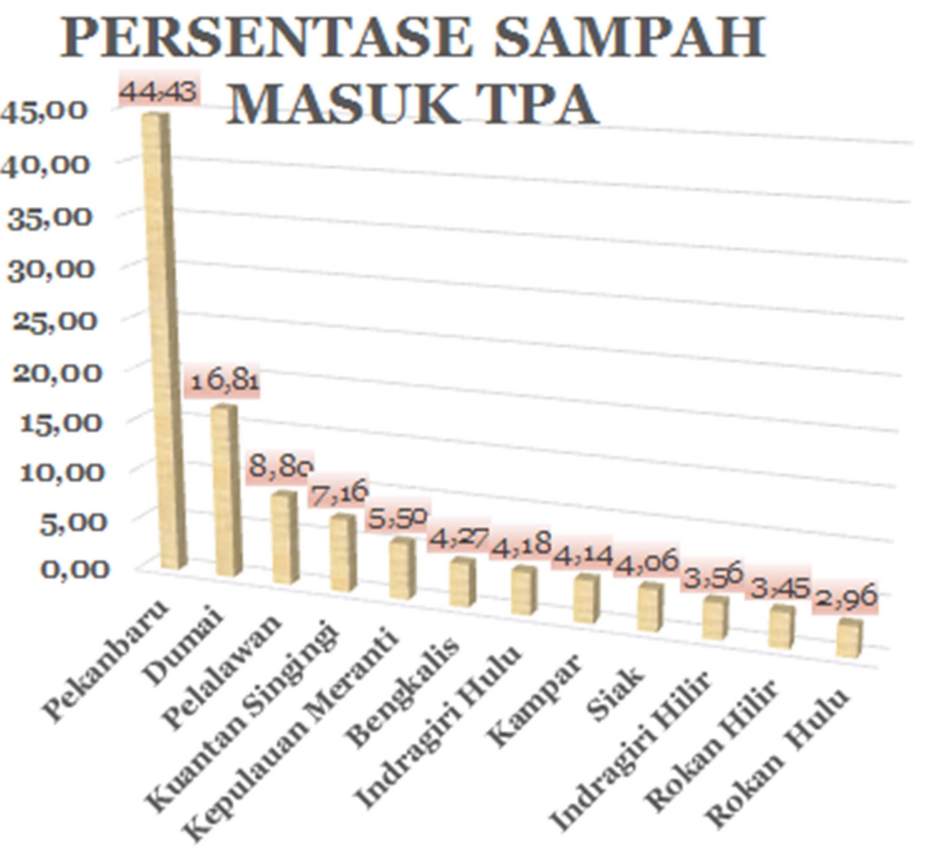

Gambar 3. Persentase sampah masuk TPA 
Tabel 2. Timbulan sampah total $\mathrm{kg} / \mathrm{hari}$

\begin{tabular}{lc}
\hline Nama Kabupaten/Kota & Timbulan Sampah Total Kg/Hari \\
\hline Pekanbaru & 837.253 \\
Kampar & 650.162 \\
Indragiri Hilir & 570.427 \\
Rokan Hilir & 529.794 \\
Rokan Hulu & 493.173 \\
Bengkalis & 441.346 \\
Siak & 362.442 \\
Indragiri Hulu & 334.186 \\
Pelalawan & 333.998 \\
Kuantan Singingi & 254.348 \\
Dumai & 233.526 \\
Kepulauan Meranti & 145.722 \\
\hline
\end{tabular}

\section{TIMBULAN SAMPAH TOTAL $\mathrm{Kg} / \mathrm{hari}$}

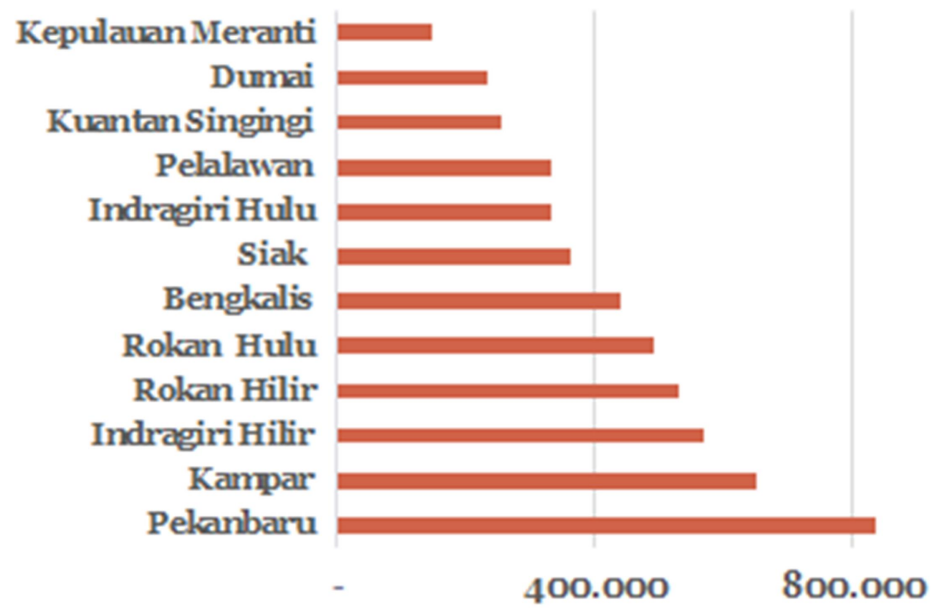

Gambar 4. Timbulan sampah total kg/hari

Tabel 3. Karakteristik Sampah Padat Kota Pekanbaru

\begin{tabular}{clr}
\hline No & Komponen Sampah & Berat (\%) \\
\hline 1 & Makanan & $47,31 \%$ \\
2 & Plastik & $15,51 \%$ \\
3 & Kertas/Karton & $11,59 \%$ \\
4 & Nappies & $6,44 \%$ \\
5 & Kayu & $4,45 \%$ \\
6 & Kebun dan Tanaman & $4,07 \%$ \\
7 & Tekstil & $3,53 \%$ \\
8 & Lain-lain & $2,87 \%$ \\
9 & Karet/Kulit & $1,92 \%$ \\
10 & Kaca & $1,45 \%$ \\
11 & Logam & $0,88 \%$ \\
\hline
\end{tabular}




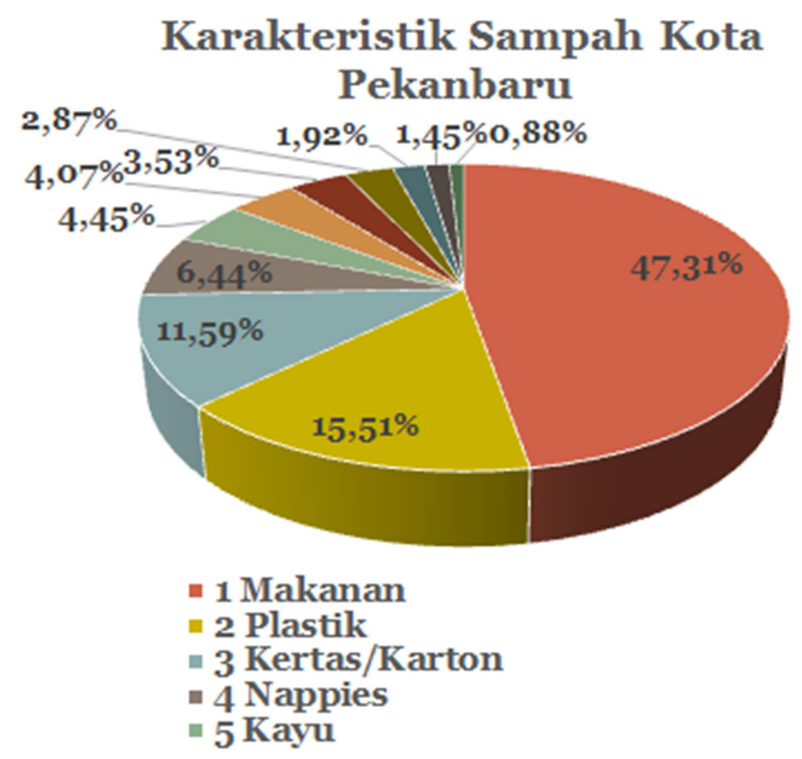

Gambar 5. Karakteristik sampah kota Pekanbaru

Setelah dilakukan penyuluhan, masing-masing peserta diberikan kesempatan untuk melihat secara langsung bagaimana cara pengolahan sampah dapur dan sampah sampah organik lainnya diolah untuk dijadikan pupuk kompos. Sehingga diharapkan masyarakat dapat memanfaatkan sampah yang selama ini tidak terpakai/terbuang untuk dijadikan produk yang bermanfaat.

\section{KESIMPULAN DAN SARAN}

Berdasarkan kegiatan yang telah dilaksanakan, maka dapat disimpulkan bahwa pemberian informasi melalui kegiatan penyuluhan kepada masyarakat sangat didukung oleh masyarakat dan perangkat desa setempat. Masyarakat antusias menyimak materi yang disampaikan dan ikut dalam praktek pengolahan sampah menjadi produk yang dapat digunakan dan juga bermanfaat.

Perlu dilakukan kembali kegiatan/program-program lainnya di lingkungan RT 03 RW 04 Kelurahan Sidomulyo Barat Kecamatan Tuahmadani Kota Pekanbaru. Antusias warga terhadap program PKM ini disambut baik, sehingga kedepannya warga ingin diadakan kembali program-program lainnya yang tentunya bermanfaat bagi masyarakat sekitar.

\section{UCAPAN TERIMAKASIH}

Tim Penyuluh mengucapkan terimakasih kepada Masyarakat dan Ketua RT 03 RW 04 Kelurahan Sidomulyo Barat Kecamatan Tuahmadani Kota Pekanbaru karena telah 
mengikuti kegiatan penyuluhan ini dengan baik dan antusias.

\section{DAFTAR PUSTAKA}

Dinas Lingkungan Hidup dan Kehutanan Provinsi Riau. 2018. Pengelolaan Sampah. hal: $10-15$.

Latifatul, Afriezal, Auliya, Kholid (2018). Pengaruh Sosialisasi Pemilahan Sampah Organik dan Non Organik serta Manajemen Sampah terhadap Penurunan Volume Sampah di Dusun Krajan Desa Kemunisari Lor Kecamatan Panti Kabupaten Jember. The Indonesian Jurnal of Health Science, Edisi Khusus, September 2018.

Pemerintah Indonesia. 2008. Undang-Undang No. 18 Tahun 2008 Yang Mengatur Tentang Pengelolaan Sampah, Jakarta. 